\title{
Cell Free Fetal DNA: Marker for Predicting Pregnancy Outcomes
}

\author{
Subir Kumar Das ${ }^{1} \cdot$ Mriganka Mouli Saha ${ }^{2}$
}

Received: 9 June 2017 / Accepted: 21 June 2017/Published online: 3 July 2017

(C) Association of Clinical Biochemists of India 2017

Healthy mother and healthy baby are the expected outcome in every pregnancy. However, maternal mortality and morbidity are major challenging issues. Preterm labour, intrauterine growth restriction (IUGR), intrauterine fetal death, fetal congenital anomalies etc. often complicate a normal pregnancy. Hypertensive disorder in pregnancy is the leading cause of maternal death in developed countries and its incidence is increasing. Approximately 830 pregnant women die every day from preventable causes worldwide, which accounts for maternal mortality ratio (MMR) 239 per 100,000 live births in developing countries and 12 per 100,000 live births in developed countries [1]. WHO has demonstrated that $85 \%$ maternal death is contributed by the African and Southeast Asian countries [1]. The MMR in India was 174 in 2015 and it contributed up to $20 \%$ maternal death worldwide [2]. Sustainable development goals (SDG) after millennium development goals (MDG) have been aimed to reduce MMR below 70 by the year 2030 [3]. Screening during antenatal period is necessary for taking preventive measures and act accordingly.

Conventional invasive prenatal testing such as amniocentesis or chorionic villous sampling for the diagnosis of

Subir Kumar Das

drsubirkdas@yahoo.co.in

1 Departments of Biochemistry, College of Medicine and JNM Hospital, WBUHS Kalyani, Nadia, West Bengal 741235, India

2 Departments of Obstetrics and Gynaecology, College of Medicine and JNM Hospital, WBUHS Kalyani, Nadia, West Bengal 741235, India fetal aneuploidies like Down syndrome (trisomy 21), Edward syndrome (trisomy 18) and Patau syndrome (trisomy 13), have procedure related risk of fetal miscarriage, limb-reduction defects, craniofacial malformations, contamination with the maternal cell and wait up to second trimester. With the advent of cell free fetal DNA (cffDNA) in the first trimester it can be used as a non-invasive prenatal diagnostic tool (NIPT) for predicting and diagnosing fetal abnormalities in utero.

cffDNA originates from the trophoblastic cells and enters into the maternal circulation invading the feto-placental barrier. cffDNA can be detected as early as 5 weeks of gestation and constitute about $10 \%$ of cell free (cf) DNA, which is cleared rapidly from maternal circulation after delivery [4]. It offers potential source of prenatal diagnosis for various genetic conditions, such as achondroplasia, autosomal recessive disorders, fetal thalassemia, aneuploidy, RhD genotyping.

cffDNA is typically fragmented hypermethylated DNA of about 150-200 bp [5]. Maternal blood collected in the EDTA vial is centrifuged at $4{ }^{\circ} \mathrm{C}$ to remove cells. It is then isolated by any of the following methods, such as: salting out method, guanidium isothiocyanate based method, triton X-100/heat/phenol chloroform method (THP); and also by using commercial kits. However, apart from cffDNA, maternal cfDNA will also be present in the samples. Promoter of RASSF1A is hypermethylated in trophoblast resulting in resistant to digestion by methylation sensitive restriction endonuclease HhaI, HpaII, Bstu1. On the contrary, maternal RASSF1A promoter is hypomethylated and sensitive to digestion by the above restriction endonucleases. Therefore, purified cfDNA is digested with the above restriction enzymes, and subsequent PCR amplification with specific primers would detect the fetal DNA [6]. 
This gender-independent detection of cell free fetal DNA in maternal plasma using RASSF1A/beta-actin has curtained off a new dimension regarding its utility to predict the adverse pregnancy outcomes. Recent studies showed the utility of cffDNA using the methylation-dependent DSCR3 and RASSF1A markers along with total cf-DNA in maternal serum by HYP2 marker are useful in predicting preeclampsia, intrauterine growth restriction (IUGR) [7]. However, variation of standardized protocol is a major issue for meta-analysis report to opine the efficacy of cffDNA in predicting pregnancy outcomes.

Funding This was self funded study.

\section{Compliance with Ethical Standards}

Conflict of interest Dr. Subir Kumar Das, and Dr. Mrignaka Mouli Saha declare that they have no conflict of interest.

Ethical approval This article does not contain any studies with human participants or animals performed by any of the authors.

\section{References}

1. Maternal mortality. Facts sheet. World health organization. http:// www.who.int/ media centre/factsheets/fs348/en. Accessed 20 July 2016.

2. Trends in maternal mortality. Geneva. WHO, UNICEF, UNFPA, World bank group, and the united nations population division. 1990 to 2015. http://data.Worldbank.org/indicator/SH.STA.MMRT Accessed 20 July 2016.

3. UN sustainable development summit. 2015 http://www.who.int/ mediacentre/events/ meetings/2015/un-sustainable-developmentsummit/en/Accessed 07 June 2017.

4. Norwitz ER, Levy B. Noninvasive prenatal testing: the future is now. Rev Obstet Gynecol. 2013;6(2):48-62.

5. Yu SCY, Chan KCA, Zheng YWL, et al. Size-based molecular diagnostics using plasma DNA for noninvasive prenatal testing. PNAS. 2014;111(23):8583-8.

6. White HE, Dent CL, Hall VJ, Crolla JA, Chitty LS. Evaluation of a novel assay for detection of the fetal marker RASSF1A: facilitating improved diagnostic reliability of noninvasive prenatal diagnosis. PLoS ONE. 2012;7(9):e45073.

7. Kim HJ, Kim SY, Lim JH, Kwak DW, Park SY, Ryu HM. Quantification and application of potential epigenetic markers in maternal plasma of pregnancies with hypertensive disorders. Int J Mol Sci. 2015;16(12):29875-88. 